\title{
The G-protein-coupled estrogen receptor agonist G-1 suppresses proliferation of ovarian cancer cells by blocking tubulin polymerization
}

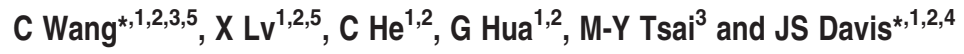

The G-protein-coupled estrogen receptor 1 (GPER) has recently been reported to mediate the non-genomic action of estrogen in different types of cells and tissues. G-1 (1-[4-(6-bromobenzo[1,3] dioxol-5yl)-3a,4,5,9b-tetrahydro-3H-cyclopenta[c]quinolin-8-yl]ethanone) was developed as a potent and selective agonist for GPER. G-1 has been shown to induce the expression of genes and activate pathways that facilitate cancer cell proliferation by activating GPER. Here we demonstrate that G-1 has an anticancer potential with a mechanism similar to vinca alkaloids, the commonly used chemotherapy drugs. We found that G-1 blocks tubulin polymerization and thereby interrupts microtubule assembly in ovarian cancer cells leading to the arrest of cell cycle in the prophase of mitosis and the suppression of ovarian cancer cell proliferation. G-1 treatment also induces apoptosis of ovarian cancer cells. The ability of G-1 to target microtubules to suppress ovarian cancer cell proliferation makes it a promising candidate drug for treatment of ovarian cancer.

Cell Death and Disease (2013) 4, e869; doi:10.1038/cddis.2013.397; published online 17 October 2013

Subject Category: Cancer

The novel G-protein-coupled estrogen receptor 1 (GPER; previously called GPR30 (G-protein-coupled receptor 30)) has important roles in many physiological actions in the body. Accumulating evidence indicates that GPER is able to mediate estrogen actions in the immune system, nervous system, renal system, cardiovascular system, and reproductive system. ${ }^{1}$ The mechanisms underlying how GPER mediates estrogen action remain unclear, primarily because estrogens are ligands for both classic estrogen receptors (ERs) and for GPER. ${ }^{1,2}$ To distinguish GPER-mediated estrogen action from that of the classic $\mathrm{ER} \alpha$ and $\mathrm{ER} \beta$, selective GPER agonists and antagonists have recently been developed ${ }^{3-5}$. Among them, G-1 (1-[4-(6-bromobenzo[1,3]dioxol-5yl)-3a,4,5,9b-tetrahydro-3H-cyclopenta[c] quinolin-8$\mathrm{yl}$-ethanone) was designed as a non-steroidal, high-affinity, and selective GPER agonist. ${ }^{3}$ Recent reports show that G-1 selectively binds to GPER, not to the classic $\mathrm{ER} \alpha$ or $\mathrm{ER} \beta .^{3,4}$ G-1 was found to be incapable of activating the estrogen response element in the promoters of estrogen response genes at concentrations from $1 \mathrm{nM}$ to $10 \mu \mathrm{M}$. $^{5}$ The specificity of $\mathrm{G}-1$ was further confirmed by a study showing that $\mathrm{G}-1$ does not significantly interact with 25 other G-protein-coupled receptors. ${ }^{6}$ G-1 has been found to mobilize intracellular calcium in COS-7 cells that transiently expressed GPER and activate phosphatidylinositide 3-kinase in $\mathrm{SKBr} 3\left(\mathrm{ER}^{-}\right.$and GPER $^{+}$) and MCF7 (ER ${ }^{+}$and $\mathrm{GPER}^{+}$) breast cancer cells. $^{3,4}$ Moreover, G-1 has been found to inhibit the chemoattractant-induced migration of SKBr3 and MCF7 cells. ${ }^{3,4}$ The above mentioned characteristics make G-1 an excellent ligand to study GPER's function under both physiological and pathological conditions.

G-1 has been extensively used to explore the biological significance of GPER in different tissues and organs, including cancer tissues. ${ }^{1}$ However, recent results are inconsistent regarding the role of GPER in cancer cell proliferation. For example, G-1 has been shown to induce the expression of genes and activate pathways that facilitate cancer cell proliferation. ${ }^{7-10} \mathrm{G}-1$ has also been shown to stimulate proliferation of certain endometrial, breast, ovarian, and testicular cancer cells. ${ }^{7,10-12}$ In contrast, Chan et al. ${ }^{13}$ demonstrated that activation of GPER by G-1 led to sustained activation of extracellular signal-regulated kinase $1 / 2$ and upregulation of $\mathrm{p} 21 \mathrm{CIP} 1$, resulting in the arrest of PC-3 prostate cancer cells at the G2 phase of mitosis.

\footnotetext{
${ }^{1}$ Olson Center for Women's Health, University of Nebraska Medical Center, Omaha, NE, USA; ${ }^{2}$ Departments of Obstetrics and Gynecology, University of Nebraska Medical Center, Omaha, NE, USA; ${ }^{3}$ Fred and Pamela Buffet Cancer Center, University of Nebraska Medical Center, Omaha, NE, USA and ${ }^{4}$ Omaha Veterans Affairs Medical Center, Omaha, NE, USA

${ }^{*}$ Corresponding author: C Wang or JS Davis, Olson Center for Women's Health, Departments of Obstetrics and Gynecology, University of Nebraska Medical Center, 985860 Nebraska Medical Center, Omaha, NE 68198-6265, USA. Tel: + 1402559 8665; Fax: + 1402559 1159; E-mail: chengwang@unmc.edu (CW) or Tel: + 1402559 9079; Fax: + 1402559 5015; E-mail: jsdavis@ unmc.edu or John.Davis30@ va.gov (JSD)

${ }^{5}$ Co-first authors.

Keywords: GPER; G-1; ovarian cancer; cell proliferation; apoptosis

Abbreviations: G-1, 1-[4-(6-bromobenzo[1,3] dioxol-5yl)-3a,4,5,9b-tetrahydro-3H-cyclopenta [c] quinolin-8-yl]-ethanone; GPER, G-protein-coupled estrogen receptor; $\mathrm{ER} \alpha$, estrogen receptor- $\alpha$; $\mathrm{ER} \beta$, estrogen receptor- $\beta$; DAPI, 4',6-diamidino-2-phenylindole; BCL-2, B-cell lymphoma 2; PARP, poly(ADP-ribose) polymerase; MTT, 3-(4,5-dimethylthiazol-2-yl)-2,5-diphenyltetrazolium bromide; AIF, apoptosis-inducing factor; MPF, mitotic-promoting factors; FBS, fetal bovine serum; DMSO, dimethyl sulfoxide; DMEM, Dulbecco's modified Eagle's medium; NuMA, nuclear mitotic apparatus protein 1; EDTA, ethylenediaminetetraacetic acid; EGTA, ethylene glycol tetraacetic acid; PMSF, phenylmethanesulfonyl fluoride; SDS, sodium dodecyl sulfate

Received 20.6.13; revised 06.9.13; accepted 09.9.13; Edited by A Stephanou
} 
Similar effects of G-1 were observed in ER-positive breast cancer cells. ${ }^{14}$ Therefore, both the function of GPER and the effect of G-1 on the proliferation of cancer cells require further investigation.

GPER has been reported to be expressed in ovarian cells and may have important physiological and pathological roles in the ovary. ${ }^{15-18}$ Furthermore, GPER has been shown to be expressed in high-risk epithelial ovarian cancer and is associated with low survival rates, ${ }^{19}$ although this conclusion has been recently challenged. ${ }^{20}$ Still, because of the existence of multiple ERs in ovarian cells, it is difficult to evaluate the function of a single ER such as GPER in these cells. In the present study, as an initial step toward understanding the function of GPER and G-1 in ovarian cancer, the effect of G-1 on the proliferation and survival of ovarian cancer cells was investigated. Contrary to above mentioned reports, in this study, we surprisingly revealed that G-1, like many anticancer drugs, targets microtubules to suppress proliferation of ovarian cancer cells. The ability of G-1 to target microtubules and prevent cell proliferation makes it a novel potential chemotherapeutic agent for ovarian cancer treatment.

\section{Results}

G-1 suppresses proliferation and induces apoptosis in ovarian cancer cells. The ovarian cancer cell lines IGROV-1 and SKOV-3 were used as cellular models of ovarian carcinoma to evaluate the effect of G-1 on ovarian cancer cell proliferation. The results show that $\mathrm{G}-1$ is able to suppress IGROV-1 cell proliferation in a concentration-dependent manner (Figure 1a). Morphologically, G-1-treated IGROV-1 cells became rounded cells within several hours and cells began to detach from the culture plate. G-1 also suppressed the proliferation of SKOV-3 cells in a concentration-dependent manner and altered the morphology of these cells within several hours (Figure 1c).

The effect of G-1 on cell-cycle progression was further investigated. Surprisingly, the results show that $\mathrm{G}-1$ treatment actually stimulates cell-cycle progression. Specifically, G-1 treatment stimulated IGROV-1 cells to transition into the S-phase of mitosis. However, G-1 treatment also significantly increased the proportion of both IGROV-1 and SKOV-3 cells in the G2/M phases of mitosis (Figures $1 \mathrm{~b}$ and d). Moreover, G-1 treatment induced apoptosis, as indicated by an increase in apoptotic cells in G-1-treated IGROV-1 and SKOV-3 cells (Figures $1 \mathrm{~b}$ and $\mathrm{d}$ ). These results reveal that the putative GPER agonist G-1 is able to promote cell-cycle progression to the S-phase and then arrest ovarian cancer cells in the G2/M prophase, leading to suppression of ovarian cancer cell proliferation and induction of ovarian cancer cell apoptosis.

G-1 arrests ovarian cancer cells in the prophase of mitosis. Given that flow cytometric analysis revealed G-1 to arrest ovarian cancer cells in the G2/M phase, experiments were designed to specify the cell-cycle stage of these G-1treated cells. The distribution of microtubules was detected by localization of $\alpha$-tubulin using fluorescent immunocytochemistry. The morphology of the nuclei was detected using 4',6-diamidino-2-phenylindole (DAPI) staining. High-resolution images show that $2 \mu \mathrm{M}$ of $\mathrm{G}-1$ treatment for $16 \mathrm{~h}$ causes cell-cycle arrest among the IGROV-1 cells during the prophase of mitosis, as indicated by the disappearance of the nuclear envelope, the appearance of microtubules in the nuclear area, and the condensation of chromosomes (Figures 2a and b).

It is well known that phosphorylation of histone $\mathrm{H} 3$ at Ser10, Ser28, and Thr11 is tightly correlated with chromosome condensation during both mitosis and meiosis, and phosphorylated histone $\mathrm{H} 3$ has been used as a mitotic marker. ${ }^{21,22}$ To confirm that G-1-treated IGROV-1 cells had entered mitosis and were arrested during the prophase, histone $\mathrm{H} 3$ phosphorylation was detected in cells treated with or without different concentrations of G-1. The treatment of IGROV-1 cells with G-1 for $16 \mathrm{~h}$ significantly increased the number of phospho-histone H3 (Ser10)-positive cells $(P<0.001)$ (Figure 2c). The phospho-histone H3 (Ser10)-positive cells in G-1-treated groups were 10-20-fold higher than that of control (Figure 2c).

Analysis of the IGROV-1 cells in different stages of cell cycle revealed that, during mitosis, $\mathrm{G}-1$ treatment significantly decreased the number of cells in interphase $(P<0.001)$ and increased the number of cells in prophase $(P<0.0001)$ (Figure 2d). Compared with the control, the cells in prophase increased more than 20-fold in $2 \mu \mathrm{M}$ G-1-treated groups (Figures 2a, b, and d). Meanwhile, G-1 treatment for $16 \mathrm{~h}$ eliminated the cells in metaphase, anaphase, telophase, and cells undergoing cytokinesis (Figures 2a, b and d).

Similar to the IGROV-1 cells, G-1 treatment also significantly decreased SKOV-3 ovarian cancer cells in the G1 phase, increased cells in the prophase (Figure 3), and eliminated cells in metaphase, anaphase, telophase, and cells undergoing cytokinesis (Figure 3 ). Compared with the control, the SKOV-3 cells in the prophase of mitosis were increased by more than 20 -fold in $2 \mu \mathrm{M}$ G-1-treated groups (Figure 3d).

G-1 treatment induces apoptosis in ovarian cancer cells through multiple mechanisms. Flow cytometry analysis revealed that $\mathrm{G}-1$ treatment is able to induce ovarian cancer cell apoptosis (Figures $1 \mathrm{~b}$ and $\mathrm{d}$ ). Therefore, experiments were designed to determine whether the interruption in cell proliferation is associated with increased apoptosis. Compared with control cells, G-1-treated IGROV-1 cells lost their cellular boundaries and normal cellular structures (Figure 4a). DAPI staining revealed that after $60 \mathrm{~h}$ of $\mathrm{G}-1$ $(2 \mu \mathrm{M})$ treatment, the nuclei of most of IGROV-1 cells were fragmented (Figure 4b). Consistent with the fragmentation of DNA, G-1 treatment of IGROV-1 cells for $24 \mathrm{~h}$ significantly increased the expression of cell-cycle inhibitor P21 CIP1 and decreased the expression of the prosurvival protein B-cell lymphoma 2 (BCL-2) (Figure 4c; for quantification see Supplementary Figure S1). In contrast, a compensatory increase in the levels of survivin was also observed, whereas these treatments had no effect on the expression of $\beta$-actin and $\beta$-tubulin (Figure $4 \mathrm{c}$ ). G-1 treatment was also found to induce cleavage of poly(ADP-ribose) polymerase (PARP) and fodrin, two important protein markers of cell apoptosis (Figure 4c). Moreover, the MTT (3-(4,5-dimethylthiazol-2-yl)2,5-diphenyltetrazolium bromide) assay showed that G-1 reduced IGROV-1 cell viability in a concentration-dependent 
a
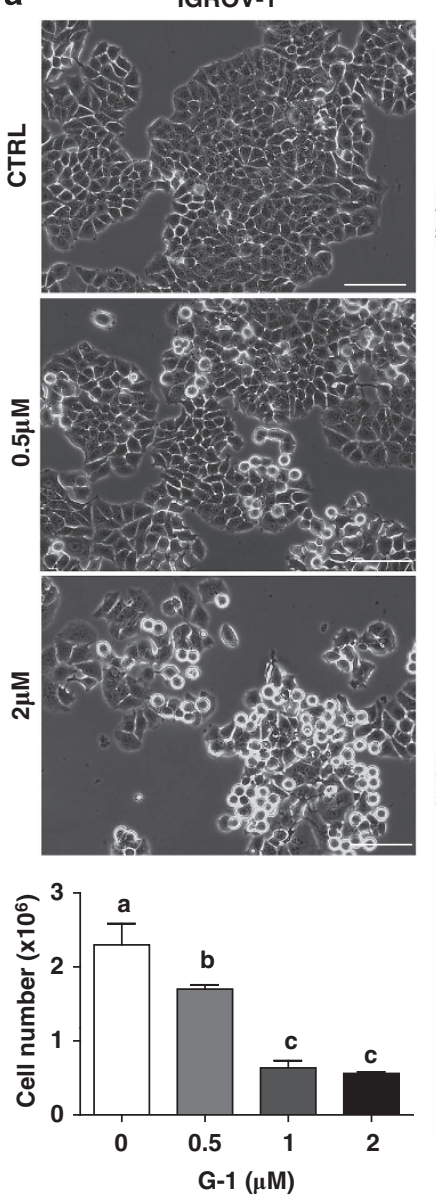

b
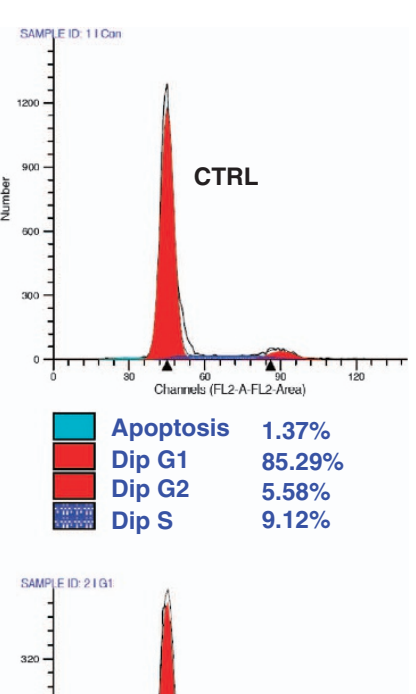

G-1

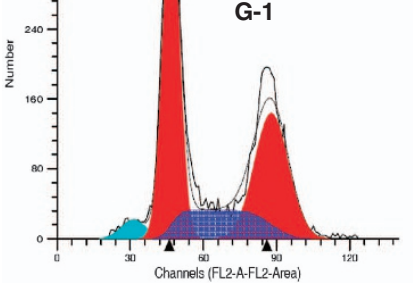

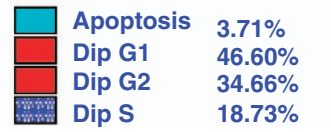

c
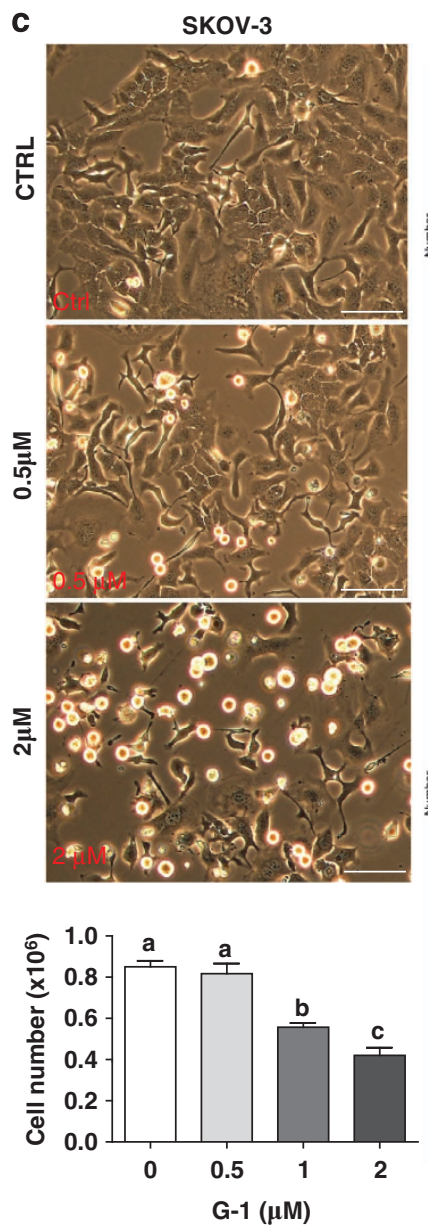

d SKOV-3
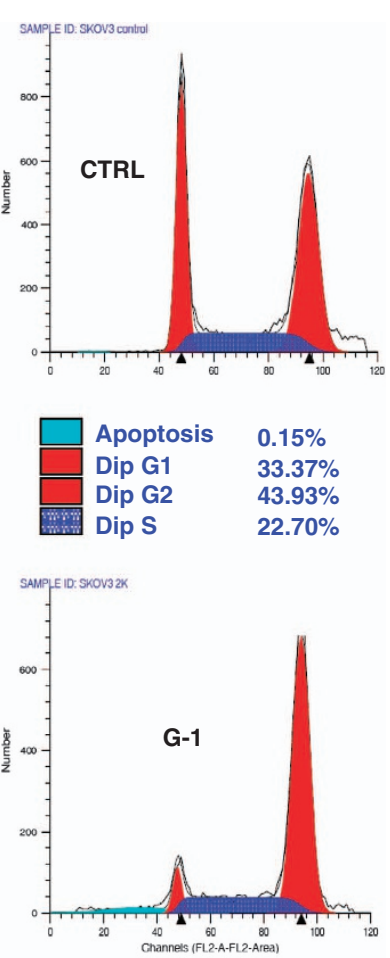

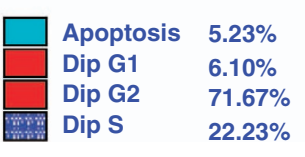

Figure 1 Effect of G-1 on the proliferation of ovarian cancer cells. (a) Representative images of the morphological change in IGROV-1 cells before (top image, control) and after treatment for $16 \mathrm{~h}$ with $0.5 \mu \mathrm{M}$ of G-1 (middle panel image) or $2 \mu \mathrm{M}$ of G-1 (lower panel image). The bar graph shows the cell number before and after treatment with increasing concentrations of $\mathrm{G}-1$ for $60 \mathrm{~h}$. Each bar represents mean \pm S.E.M. Bars with different letters are significantly $(P<0.05)$ different from each other. Scale bars, $50 \mu \mathrm{m}$. (b) Effect of G-1 on the cell-cycle progression of IGROV-1 cells. CTRL: DMSO (0.1\% in the medium) control; G-1: cells treated with $2 \mu \mathrm{M}$ of G-1 for $16 \mathrm{~h}$. (c) Representative images show the morphology of SKOV-3 cells before (top image, control) and after treatment for $16 \mathrm{~h}$ with $0.5 \mu \mathrm{M}$ of G-1 (middle panel image) or $2 \mu \mathrm{M}$ of G-1 (lower panel image). Scale bars, $50 \mu \mathrm{m}$. The bar graph shows the SKOV-3 cell number before and after treatment with different concentrations of G-1 for $60 \mathrm{~h}$. Each bar represents a mean cell number \pm S.E.M. Bars with different letters are significantly $(P<0.05)$ different from each other. (d) Effect of $\mathrm{G}-1$ on the cell-cycle progression of SKOV-3 cells. CTRL, DMSO (0.1\% in the medium) control; G-1: cells treated with $2 \mu \mathrm{M}$ of G-1 for $16 \mathrm{~h}$

manner (Figure 4d). Taken together, these results suggest that G-1 treatment induces ovarian cancer cell apoptosis.

To further understand the mechanisms underlying G-1induced cell apoptosis, caspase $3 / 7$ activities were measured before and after G-1 treatment. Treatment of IGROV-1 cells with $2 \mu \mathrm{M}$ of $\mathrm{G}-1$ for $16 \mathrm{~h}$, a time point when nearly $40-50 \%$ of cells began to detach from the culture plate after treatment, did not affect caspase 3/7 activities (Figure 4e). Next, IGROV-1 cells were treated with $2 \mu \mathrm{M} \mathrm{G}-1$ for $2-24 \mathrm{~h}$ to detect whether G-1 activated caspase 3/7 in IGROV-1 cells at earlier time points. Surprisingly, no significant changes in caspase $3 / 7$ activity were observed at any time point (from 2 to $24 \mathrm{~h}$ ) (Figure 4e) despite the marked changes in cellular morphology. This suggests that G-1 induces IGROV-1 cell apoptosis in a caspase $3 / 7$-independent manner. To confirm this, IGROV-1 cells were treated with or without G-1 for $16 \mathrm{~h}$. Western blot and fluorescent immunohistochemistry were used to detect the expression and location of apoptosisinducing factor (AIF), a central protein involved in the process of caspase-independent cell apoptosis. Western blot results showed that G-1 treatment did not change the level of AIF protein (data not shown). However, fluorescent immunocytochemistry results showed that G-1-induced translocation of AIF from the cytoplasm (mitochondria) to the nuclear area (Figure 4f). These results suggest that G-1 induces IGROV-1 cell apoptosis in a caspase 3/7-independent manner.

Treatment with G-1 also induced cell apoptosis in the SKOV-3 cells, as shown by dramatic changes in cellular morphology (Figure 5a), DNA fragmentation (Figure 5b), and significant increases in the cleaved PARP and fodrin (Figure 5c; for quantification see Supplementary Figure S2). Similar to results observed that in the IGROV-1 cells, G-1 treatment of the SKOV-3 cells also led to an increase in the expression of P21CIP1 and a decrease in the expression of BCL-2 (Figure 5c, Supplementary Figure S2). Moreover, G-1 treatment resulted in a decrease in the cell viability, as detected by the MTT assay (Figure $5 \mathrm{~d}$ ). However, in contrast to IGROV-1 cells, treatment of SKOV-3 cells with G-1 for $16 \mathrm{~h}$ 
a

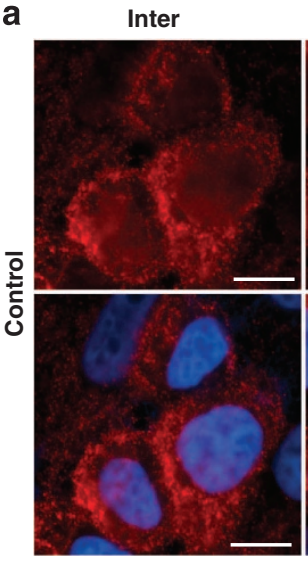

b

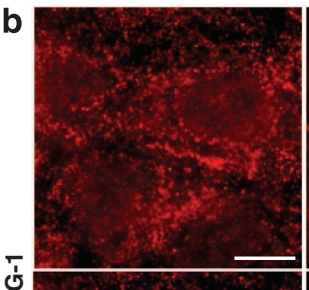

जั

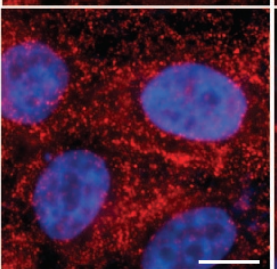

L-G2
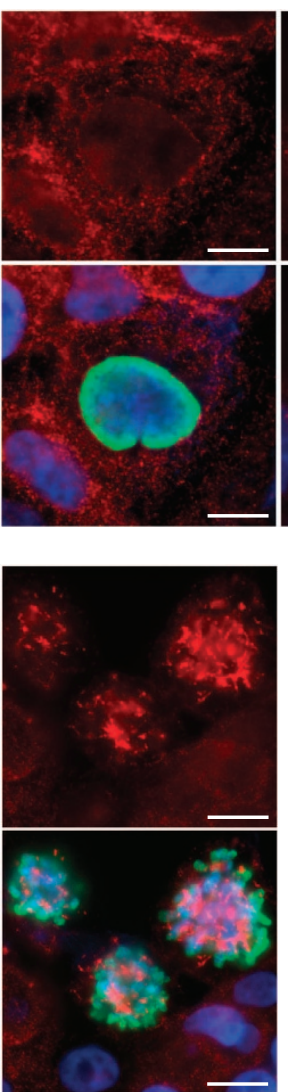

Pro

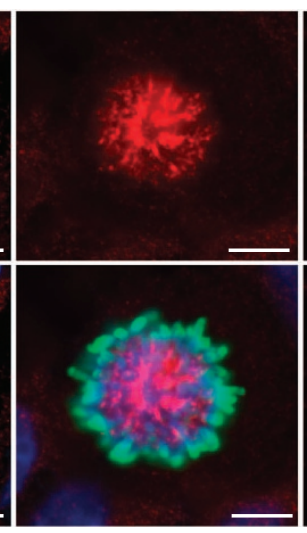

C

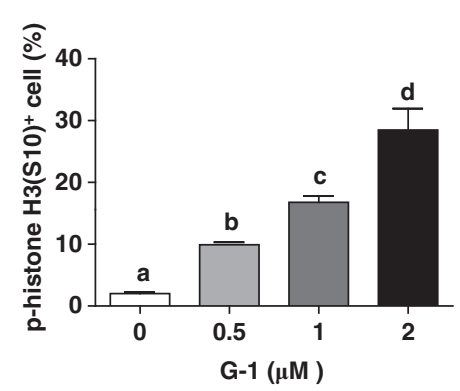

Meta

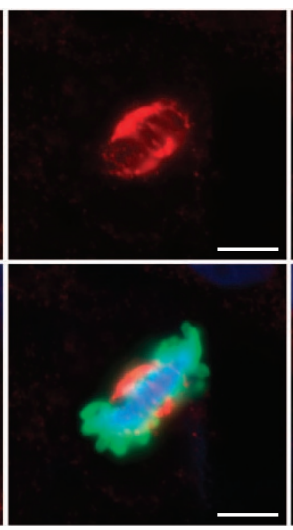

Ana

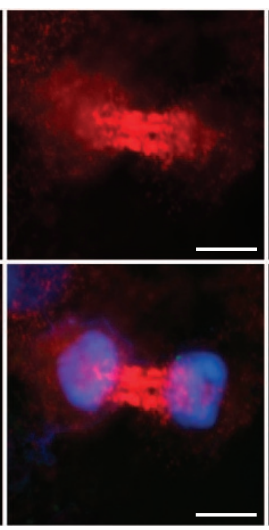

Telo+Cytk

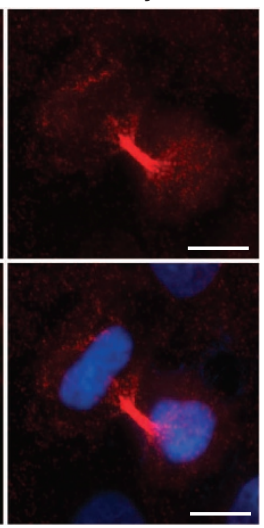

d

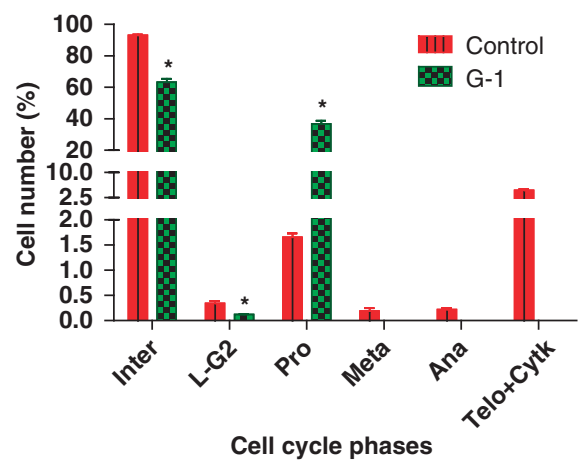

Figure 2 Effect of G-1 on the cell-cycle progression of IGROV-1. (a) Microtubule structure and distribution of phosphorylated histone H3 (Ser10) in IGROV-1 cells during the normal cell cycle. Top panels: distribution of microtubule shown by $\alpha$-tubulin staining (red), lower panels: combination of microtubule marker (red) and phosphorylated histone H3 (green) in the IGROV-1 cells during the normal cell cycle. Nuclei were stained with DAPI. Inter, interphase; L-G2, late G2 phase; Pro, prophase; Meta, metaphase; Ana, anaphase; Telo + Cytk, telophase and cytokinesis. Scale bars, $10 \mu \mathrm{m}$. (b) Microtubule structure (red) and distribution of phosphorylated histone H3 (green) in IGROV-1 cells after treatment with $2 \mu \mathrm{M}$ of G-1 for $16 \mathrm{~h}$. Scale bars, $10 \mu \mathrm{m}$. (c) Percentage of cells staining positive for phosphorylated histone H3 (Ser10). Each bar represents the mean \pm S.E.M. Bars with different letters are significantly $(P<0.05)$ different from each other. (d) Percentage of cells in different stages of the cell cycle. Each bar represents the mean \pm S.E.M. Bars with "*' are significantly $(P<0.05)$ different from control

significantly increased caspase $3 / 7$ activities (Figure $5 e$ ). This result suggests that $\mathrm{G}-1$ induces apoptosis of SKOV-3 cells in a caspase 3/7-dependent manner.

\section{G-1 treatment does not inhibit activation of mitotic-} promoting factors and G2/M entry checkpoint key proteins. To explore the mechanism of G-1 action, experiments were designed to determine whether G-1 treatment inhibits mitotic-promoting factors (MPF) and/or key protein kinases controlling the cell-cycle entry into the G2/M phase of mitosis. In both IGROV-1 and SKOV-3 cells, treatment with increasing concentrations of G-1 stimulated phosphorylation of histone H3 (S10), Aurora A (T288), Aurora B (T232), and cdc25 (T48), whereas this treatment suppressed phosphorylation of Wee1 (S642) and cdc2 (Y15) (Figures 6a and b; for quantification see Supplementary Figures S3 and S4). G-1 treatment activates MPF in a concentration-dependent manner. At a concentration of $1 \mu \mathrm{M}, \mathrm{G}-1$ activated MPF to the maximum point (Figures $6 a$ and b, Supplementary Figures S3 and S4). G-1 also significantly increased the phosphorylation of NuMA (nuclear mitotic apparatus protein 1; S395), a critical factor for proper segregation of chromosomes during mitosis ${ }^{23}$ (Figures $6 a$ and b, Supplementary Figures S3 and S4). In contrast, G-1 treatment had no effect on protein levels of $\beta$-tubulin. These results indicate that $\mathrm{G}-1$ treatment does not inhibit the activation of MPF or critical factors for mitotic entry in ovarian cancer cells.

G-1 suppresses ovarian cancer cell proliferation by targeting tubulin. The spindle checkpoint has an important role in cell-cycle regulation. ${ }^{23}$ Staining $\alpha$-tubulin showed that IGROV-1 and SKOV-3 cells treated with G-1 formed more than two spindle asters, suggesting the possible formation of multiple spindles (Figures $2 \mathrm{~b}$ and $3 \mathrm{~b}$ ). Therefore, additional experiments were designed to determine the function of G-1 in spindle formation. The cultured IGROV-1 cells were first placed on ice for $1 \mathrm{~h}$, which depolymerizes all microtubules in the cells. The ice-cold medium was then replaced with prewarmed medium $\left(37^{\circ} \mathrm{C}\right)$ containing vehicle (control) or $2 \mu \mathrm{M}$ G-1. Next, the cells were incubated at $37^{\circ} \mathrm{C}$ for an additional $1 \mathrm{~h}$ to allow microtubule repolymerization and mitotic spindle reassembly. It was observed that incubation on ice caused depolymerized microtubules in the IGROV-1 cells, which was indicated by the disappearance of microtubules and spindle 
a
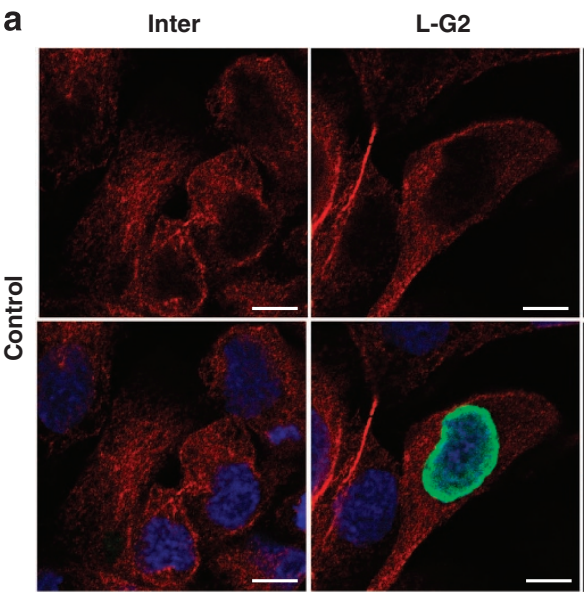

b
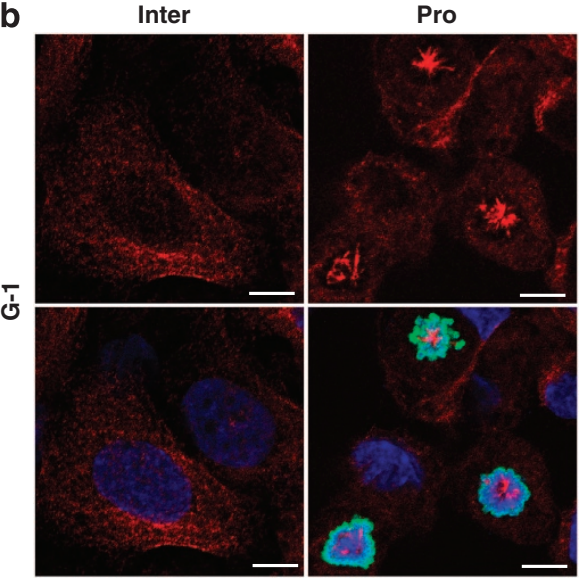

Pro

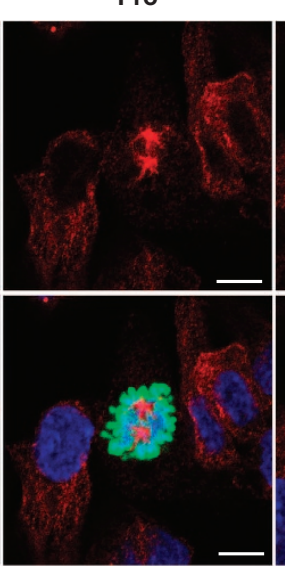

C

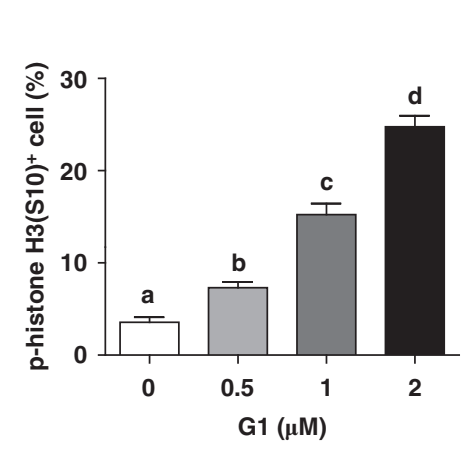

Meta

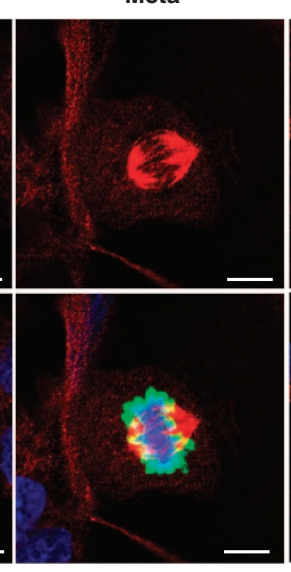

Ana

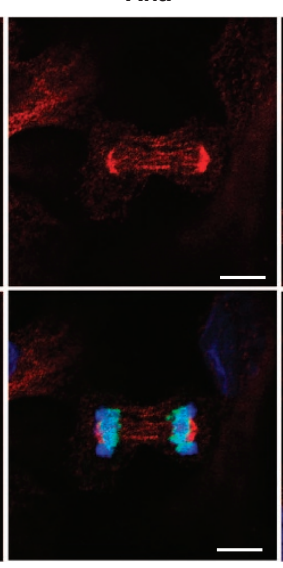

Telo+Cytk

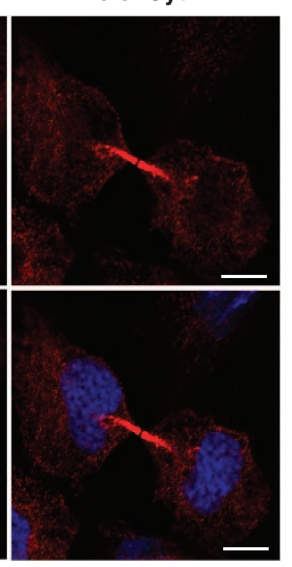

d

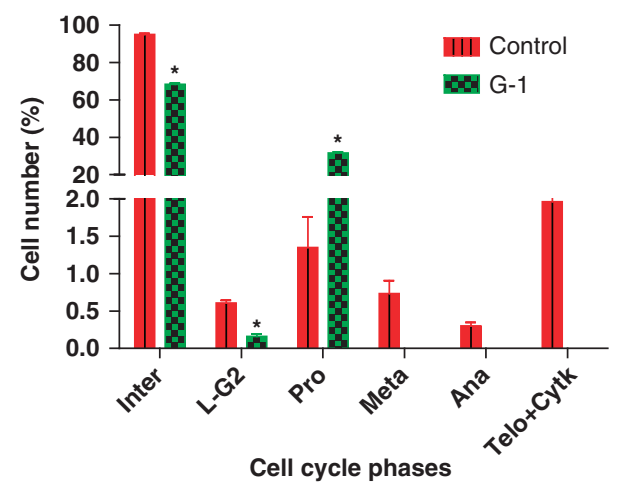

Figure 3 Effect of G-1 on the cell-cycle progression of SKOV-3 ovarian cancer cells. (a) Microtubule structure and distribution of phosphorylated histone H3 (Ser10) in SKOV-3 cells during the normal cell cycle. Top panels: distribution of microtubules shown by $\alpha$-tubulin staining (red), lower panels: combination of microtubule marker (red) and phosphorylated histone H3 (green) in the SKOV-3 cells during the normal cell cycle. Nuclei were stained with DAPI. Inter, interphase; L-G2, late G2 phase; Pro, prophase; Meta, metaphase; Ana, anaphase; Telo + Cytk, telophase and cytokinesis. Scale bars, $10 \mu \mathrm{m}$. (b) Microtubule structure (red) and distribution of phosphorylated histone H3 (green) in SKOV-3 cells after treatment with $2 \mu \mathrm{M}$ of G-1 for $16 \mathrm{~h}$. Scale bars, $10 \mu \mathrm{m}$. (c) Percentage of cells staining positive for phosphorylated histone H3 (Ser10). Each bar represents the mean \pm S.E.M. Bars with same letter are not significantly $(P<0.05)$ different from each other. (d) Percentage of the cells in different stages of the cell cycle. Each bar represents the mean \pm S.E.M. Bars with “*' are significantly $(P<0.05)$ different from the control

structures in ice-incubated cells (Figures 7a-1 and a-2). After the control cells were warmed to $37^{\circ} \mathrm{C}$ and incubated for $1 \mathrm{~h}$, the microtubules successfully repolymerized, as indicated by the appearance of microtubules in all cells and the formation of spindles in the cells in metaphase and anaphase (Figures 7a-3 and a-4). However, in the G-1-treated cells, no normal spindle structures were observed. Instead, microtubules in the G-1-treated cells formed many microtubule asters (Figures 7a-5 and a-6), suggesting that G-1 targets tubulin and interferes with cellular microtubule assembly and spindle formation. To further confirm this finding, an in vitro tubulin polymerization assay kit was used to determine whether G-1 affects the tubulin polymerization and microtubule assembly. As expected, paclitaxel (positive control) stabilized and enhanced microtubule assembly, whereas nocodazole (negative control) interfered with tubulin polymerization and blocked microtubule assembly (Figure $7 \mathrm{~b}$ ). Compared with the dimethyl sulfoxide (DMSO) control, G-1 treatment effectively blocked tubulin polymerization and microtubule assembly (Figure $7 \mathrm{~b}$ ). These results strongly suggest that
G-1 arrests ovarian cancer cells in the prophase of mitosis by blocking tubulin polymerization and microtubule assembly.

\section{Discussion}

The non-steroidal ligand G-1 was developed as a GPERselective agonist in order to differentiate GPER-mediated estrogenic action from that mediated by $\operatorname{ER} \alpha$ and $\operatorname{ER} \beta .^{3}$ Following the original study clearly demonstrating G-1 to be a high-affinity and GPER-selective agonist, G-1 has been widely used to study the functions and mechanisms of GPER-mediated estrogenic action in different tissues and organs. ${ }^{1}$ Owing to the discrepant results obtained by different groups regarding the effect of G-1 on cancer cell proliferation, ${ }^{7-9,13,14,24}$ the present study was initiated to clarify the action of $\mathrm{G}-1$ on the proliferation and survival in ovarian cancer cells. In the present study, G-1 was found to suppress ovarian cancer cell proliferation in a concentrationdependent manner. For example, G-1 treatment led to changes in cell morphology within $6-16 \mathrm{~h}$ in both IGROV-1 

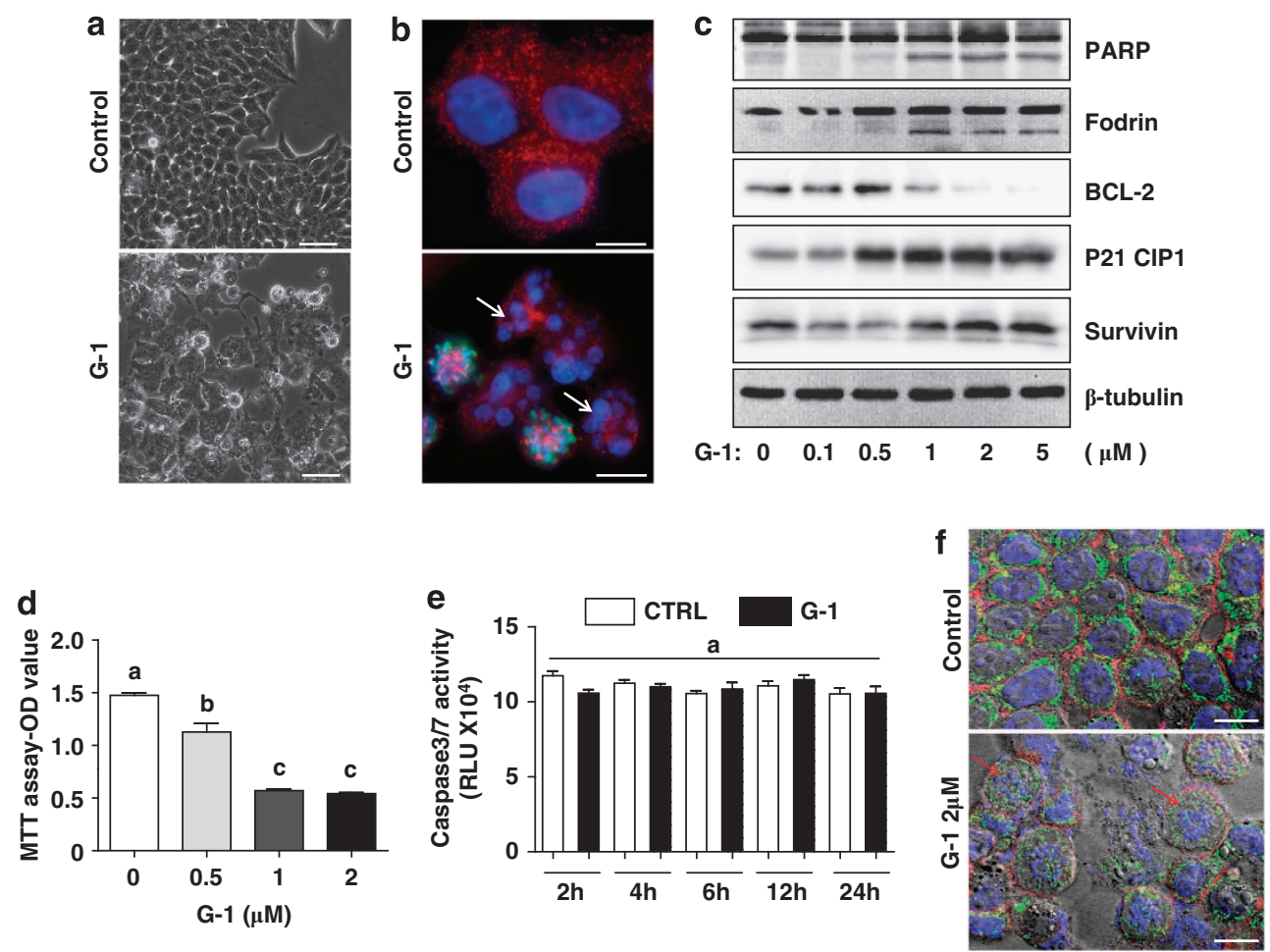

Figure 4 Evidence for G-1 induction of apoptosis in IGROV-1 cells. (a) IGROV-1 cells were treated with or without G-1 (2 $\mu \mathrm{M})$ for $48 \mathrm{~h}$. Compared with the control (top panel), the morphology of IGROV-1 cells drastically changed in the G-1-treated groups (lower panel). The cellular borders in the treated groups disappeared. Scale bars, $40 \mu \mathrm{m}$. (b) Compared with the control group (top panel), G-1 treatment $(2 \mu \mathrm{M}, 60 \mathrm{~h})$ induced dramatic DNA fragmentation (lower panel). Red is $\alpha$-tubulin. Green is phosphohistone H3 (Ser10). Nuclei were stained with DAPI. Arrows point to the fragmented DNA. Scale bars, $10 \mu \mathrm{m}$. (c) Western blot analysis of molecules associated with cell apoptosis in the IGROV-1 cells treated with or without different concentrations of G-1 for $24 \mathrm{~h}$. Results are from a representative experiment. Quantitative results from multiple experiments are presented in Supplementary Figure S1. (d) The MTT assay shows that G-1 treatment $(2 \mu \mathrm{M}, 48 \mathrm{~h})$ significantly reduces cell viability. (e) IGROV-1 cells were treated with or without $2 \mu \mathrm{M}$ of G-1 for 2-24h. Caspase 3/7 activity assay shows that G-1-induced apoptosis in the IGROV-1 cells that are caspase 3/7 independent. (f) Localization of AIF (green) in IGROV-1 cells treated with or without $2 \mu \mathrm{M}$ G-1 for $24 \mathrm{~h}$. Notice the translocation of AIF from cytosol to the nuclear area after G-1 treatment. Red is $\alpha$-tubulin. Nuclei were stained with DAPI. Arrows point to the nuclear-localized AIF. Scale bars, $10 \mu \mathrm{m}$

and SKOV-3 ovarian cancer cells, leading to detachment of cells from the culture plate and cell death. The same effect was also observed in CAOV-3 and HEK-293 cells, and MDA-MB 231 (data not shown). Treatment of ovarian cancer cells in vitro with G-1 for an extended period of time ( $>48 \mathrm{~h}$ ) significantly suppressed the proliferation of ovarian cancer cells. These results are inconsistent with the observations that activation of GPER is associated with upregulation of genes and activation of signaling pathways that promote cell proliferation. ${ }^{6,7,9,24-27}$ One explanation for these discrepancies is that the function of GPER on cell proliferation may depend on cell or tissue types, which may have differential expression levels of GPER. However, recent studies have shown that that G-1 is able to regulate cellular functions in a GPER-independent manner. ${ }^{28,29}$

In the present study, flow cytometry was used to detect the effect of G-1 on ovarian cancer cell-cycle progression. We found that G-1 treatment significantly decreases the portion of cells in G1 phase and drastically increases the percentage of cells in G2/M phases. However, these results are inconsistent with the deceased cell number after G-1 treatment, suggesting that G-1 treatment may arrest the cell cycle in either the $\mathrm{G} 2$ or the $M$ phase. Microscopy of nuclear morphology showed that in the G-1-treated cells, the nuclear membrane had already disappeared, chromosomes had condensed, and microtubules had invaded into the nuclear space, indicating that these cells actually had already entered into mitosis. Interestingly, more than three spindle asters were observed in most of the cell-cycle-arrested cells. Normal spindles did not form and the chromosomes did not properly align to form the metaphase plate, suggesting that the cells were arrested in the prophase of mitosis and did not progress into later stage of the cell cycle.

It is well known that phosphorylation of histone $\mathrm{H} 3$ at Ser10, Ser28, and Thr11 is tightly correlated with chromosome condensation during both mitosis and meiosis. This feature has been used as a marker of cellular mitotic entry. ${ }^{22}$ G-1 treatment of IGROV-1 and SKOV-3 ovarian cancer cells led to a significant increase in the number of phosphorylated histone H3 (Ser 10)-positive cells. This biochemical result confirms the morphological observation in this study that G-1 treatment arrested cells in the prophase of mitosis. This result also indicates that G-1 treatment does not inhibit histone activation during cell division.

In the current study, G-1 treatment not only suppressed cell proliferation, but also induced ovarian cancer cell apoptosis. This is supported by the following experimental results: (1) flow cytometric analysis indicated a significant increase in 
a

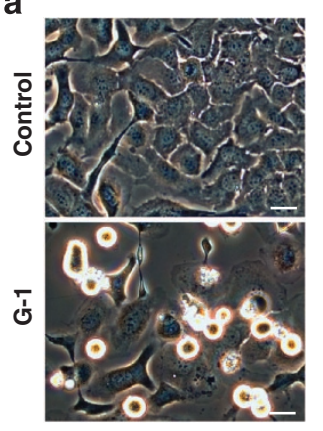

b

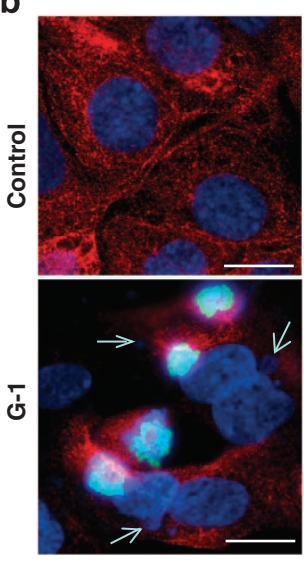

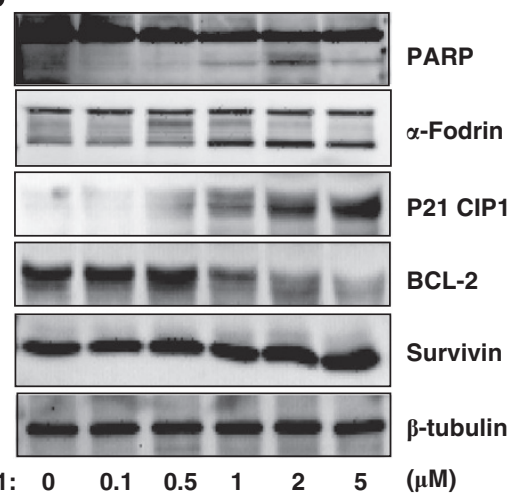

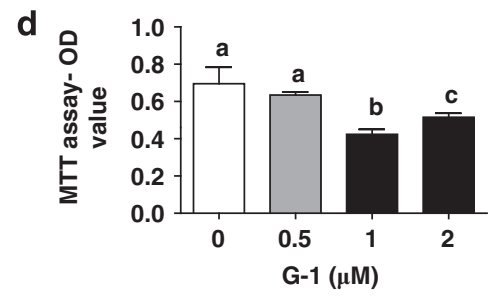

e

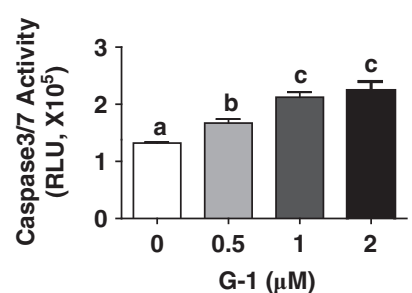

Figure 5 Evidence that G-1 induces apoptosis of SKOV-3 ovarian cancer cells. (a) The morphology of SKOV-3 ovarian cancer cells drastically changed in the G-1-treated groups ( $2 \mu \mathrm{M}, 48 \mathrm{~h}$; lower panel) compared with the control (top panel). Floating cells and apoptotic bodies in the G-1-treated SKOV-3 cells suggest that G-1 induces apoptosis in SKOV-3 cells. Scale bars, $20 \mu \mathrm{m}$. (b) Compared with the control group (top panel), G-1 treatment ( $2 \mu \mathrm{M}, 60 \mathrm{~h})$ induced dramatic DNA fragmentation in SKOV-3 cells (lower panel). Red is $\alpha$-tubulin. Green is phospho-histone H3 (Ser10). Nuclei were stained with DAPI. Arrows point to the fragmented nuclei. Scale bars, $10 \mu$ m. (c) SKOV-3 cells were treated with different concentrations of G-1 for $24 \mathrm{~h}$. Molecules associated with cell apoptosis were detected by western blot. Results are from a representative experiment. Quantitative results from multiple experiments are presented in Supplementary Figure S2. (d) SKOV-3 cells were treated with different concentrations of G-1 for $48 \mathrm{~h}$. Cell viability was detected with MTT assay. (e) SKOV-3 cells were treated with different concentrations of G-1 for $24 \mathrm{~h}$. The caspase $3 / 7$ activity assay shows that G-1induced apoptosis in a caspase-dependent manner in SKOV-3 cells

apoptotic cells in both IGROV-1 and SKOV-3 cells treated with G-1; (2) confocal microscopy showed drastic fragmentation of the nuclei in G-1-treated IGROV-1 and SKOV-3 cells; (3) the MTT assay indicated a significant reduction in the viability of G-1-treated IGROV-1 and SKOV-3 cells; and (4) western blot analysis indicated a significant increase in the cyclindependent kinase inhibitor P21 CIP1 and a significant decrease in the prosurvival protein $\mathrm{BCL}-2$ in $\mathrm{G}$-1-treated IGROV-1 and SKOV-3 cells.

Nuclear PARP and the membrane-associated cytoskeleton protein fodrin have important roles in the maintenance of cell viability by regulating key cellular processes. PARP is critical for proper DNA replication, damage detection, repair, and recombination. ${ }^{30,31}$ Fodrin is important for maintaining the normal membrane structure and supporting cell-surface protein functions. ${ }^{32}$ Cleavage of PARP effectively neutralizes its ability to participate in DNA repair and contributes to the commitment of a cell to undergo apoptosis. ${ }^{33,34}$ Cleavage of fodrin leads to miscommunication and dysfunction of membrane proteins and cell shrinkage. ${ }^{33,34}$ Therefore, cleavage of PARP and fodrin facilitates cellular disassembly and also serves as markers for cells undergoing apoptosis. ${ }^{31}$ Results from the present study show that G-1 significantly increased the level of cleaved fodrin and PARP in a concentrationdependent manner, thus further confirming that G-1 treatment induces cell apoptosis.
PARP can be cleaved by many IL-I $\beta$-converting enzymelike caspases in vitro, ${ }^{35}$ and is one of the main cleavage targets of caspase 3 in vivo. ${ }^{36}$ Likewise, $\alpha$-fodrin is the primary target of caspases during apoptosis. Results in the present study showed that G-1 treatment $(2 \mu \mathrm{M}, 16 \mathrm{~h})$ significantly increased caspase 3/7 activity in SKOV-3 cells, suggesting that $\mathrm{G}-1$ induces apoptosis in these cells through a traditional caspase-dependent signaling pathway. However, G-1 treatment did not alter caspase 3/7 activity in IGROV-1 cells, despite increases in the level of cleaved PARP and fodrin. One possible explanation for this is that other pathways of caspase-independent apoptosis are involved in G-1-induced apoptosis of the IGROV-1 cells.

Recent studies showed that mitochondria can release factors involved in caspase-independent cell death. AIF is believed to have a central role in the regulation of caspaseindependent cell death. ${ }^{37}$ Following an apoptotic stimulus, mitochondrial AIF is released and is translocated to the nucleus where it induces chromatin condensation in a caspase-independent manner, subsequently causing cell death. In an effort to explain how G-1 induces apoptosis in IGROV-1 cells, the expression and location of the AIF protein was determined in IGROV-1 cells treated with or without G-1. AIF was found to be expressed in IGROV-1 cells, and G-1 treatment induced nuclear translocation of AIF and condensation of chromatin. Therefore, depending on the cell types, 
a

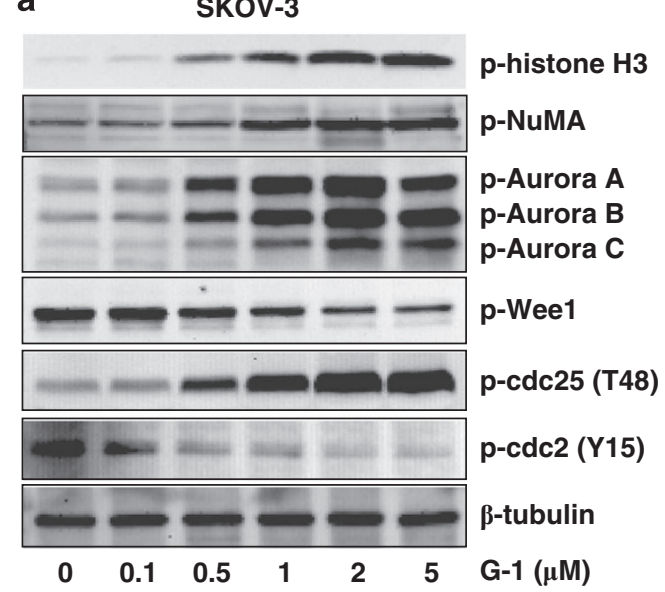

b

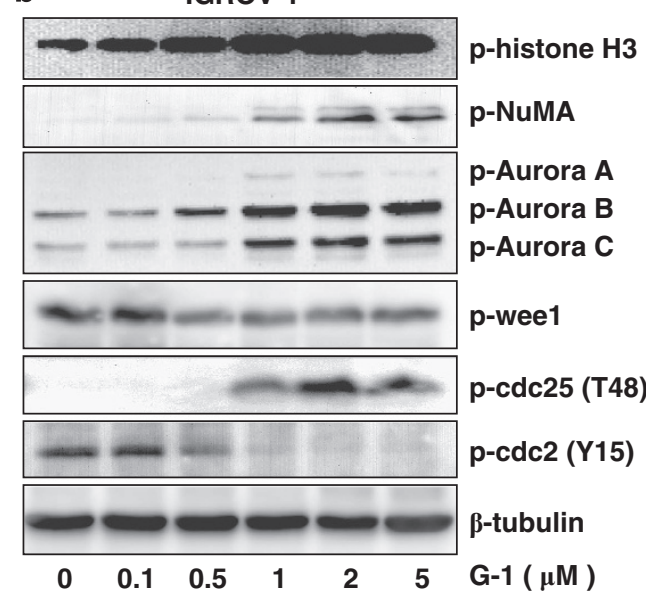

Figure 6 Effect of G-1 treatment on the expression and activation of proteins associated with mitosis entry in the cultured (a) SKOV-3 and (b) IGROV-1 cells. Cells were treated with different concentrations of $\mathrm{G}-1$ for $16 \mathrm{~h}$. Molecules associated with cell-cycle progression were detected by western blot. Results are from a representative experiment. Quantitative results from multiple experiments are presented in Supplementary Figures S3 and S4

G-1 appears to be able to induce ovarian cancer cell apoptosis both in caspase-dependent and capsase-independent pathways.

To understand the mechanism(s) underlying the G-1 suppression of ovarian cancer cell proliferation, we evaluated the expression and activation state of key molecules governing cell-cycle progression. For eukaryotic cells, successful progression of mitosis is intensively monitored and subtly controlled by many biological mechanisms. The G2/M DNA damage checkpoint is a mechanism that prevents the cell from entering mitosis if the DNA is damaged. The cdc2-cyclin $B$ kinase is pivotal in regulating this transition. During late $\mathrm{G} 2$ phase, cdc2 is phosphorylated at $\mathrm{T} 14$ and $\mathrm{Y} 15$ by the protein kinases Wee1 and Myt1, and maintained in an inactive state. ${ }^{38}$ As cells approach the $\mathrm{M}$ phase, the phosphatase cdc25 activates cdc2 by dephosphorylating cdc2 at T14 and Y15, and subsequently establishes a feedback amplification loop that efficiently drives cells to mitosis. ${ }^{38}$ The data in the present study show that G-1 treatment leads to decreased phosphorylation of Wee1, increased phosphorylation of cdc25, and significantly decreased phosphorylation of cdc2 at Y15. G-1 treatment also significantly increased phosphorylation of NuMA and Aurora kinase, two factors whose activations are critical for proper mitotic entry. These results indicate that G-1 treatment does not affect the activation of key molecules governing the mitotic entry in the IGROV-1and SKOV-3 ovarian cancer cells.

Results from the present study demonstrate that the inhibitory effects of G-1 on cell proliferation are not explained by a disruption of the molecular control of cell-cycle progression, considering that histone H3 and MPF activity was normal after G-1 treatment. However, it was clearly observed that cells were unable to progress past the prophase of the mitosis. Importantly, the spindle assembly checkpoint is another critical mechanism that monitors the proper segregation of chromosomes by preventing cell-cycle progression from entering anaphase until after all chromosomes have correctly attached to the spindle. ${ }^{39}$ immunocytochemistry results showed that multiple spindle-like structures were formed in the G-1-treated cells, implying that the factors involved in the normal spindle formation was interrupted by G-1 treatment. Several critical factors that control the formation of centrosomes and spindle pole were then investigated. The results showed that these factors are also properly activated or localized (data not shown).

It is well known that microtubules, the main components of the mitotic spindle, are a target of many anticancer drugs. Therefore, experiments in the present study were designed to determine whether G-1 has an effect on the assembly of microtubules. For this purpose, the spindle in the IGROV-1 cells was temporarily disassembled by depolymerizing microtubules at low temperature. Upon warming, in order to reassemble microtubules, G-1 treatment was found to completely block spindle formation, suggesting that G-1 targets microtubule assembly. Using an in vitro tubulin polymerization assay, G-1 was found to be able to directly prevent polymerization of tubulin and disrupt assembly of microtubules. Taken together, these results suggest that G-1, the putative GPER agonist, suppresses ovarian cancer cell proliferation and induces cancer cell apoptosis by targeting tubulin to block spindle formation.

In conclusion, this study indicates that G-1 targets tubulin to block microtubule assembly and spindle formation of ovarian cancer cells leading to cancer cell-cycle arrest and apoptosis. The inhibitory effect of G-1 on ovarian cancer cell growth indicates that G-1 may be a promising candidate drug for ovarian cancer therapy.

\section{Materials and Methods}

Chemicals. G-1 was purchased from Tocris Bioscience (Ellisville, MO, USA). Dimethyl sulfoxide (DMEM) and other cell culture mediums were purchased from Invitrogen (Carlsbad, CA, USA). Fetal bovine serum (FBS) were purchased from HyClone Laboratories Inc. (Logan, UT, USA). Alexa-conjugated secondary antibodies were purchased from Molecular Probes, Inc. (Eugene, OR, USA). Antibodies against human PARP, $\alpha$-fodrin, AIF, $\alpha$-tubulin, P21 cip1, cyclin B1, BCL-2, phospho-Aurora, phospho-histone $\mathrm{H} 3$ (Ser10), phosphorylated and nonphosphorylated cdc2, Wee1, and NuMA, as well as horseradish peroxidaseconjugated secondary antibodies were purchased from Cell Signaling Technology, Inc. (Danvers, MA, USA). The $\beta$-actin and $\beta$-tubulin antibodies were purchased from Sigma-Aldrich (St. Louis, MO, USA). The pericentrin-2 antibody was 
a
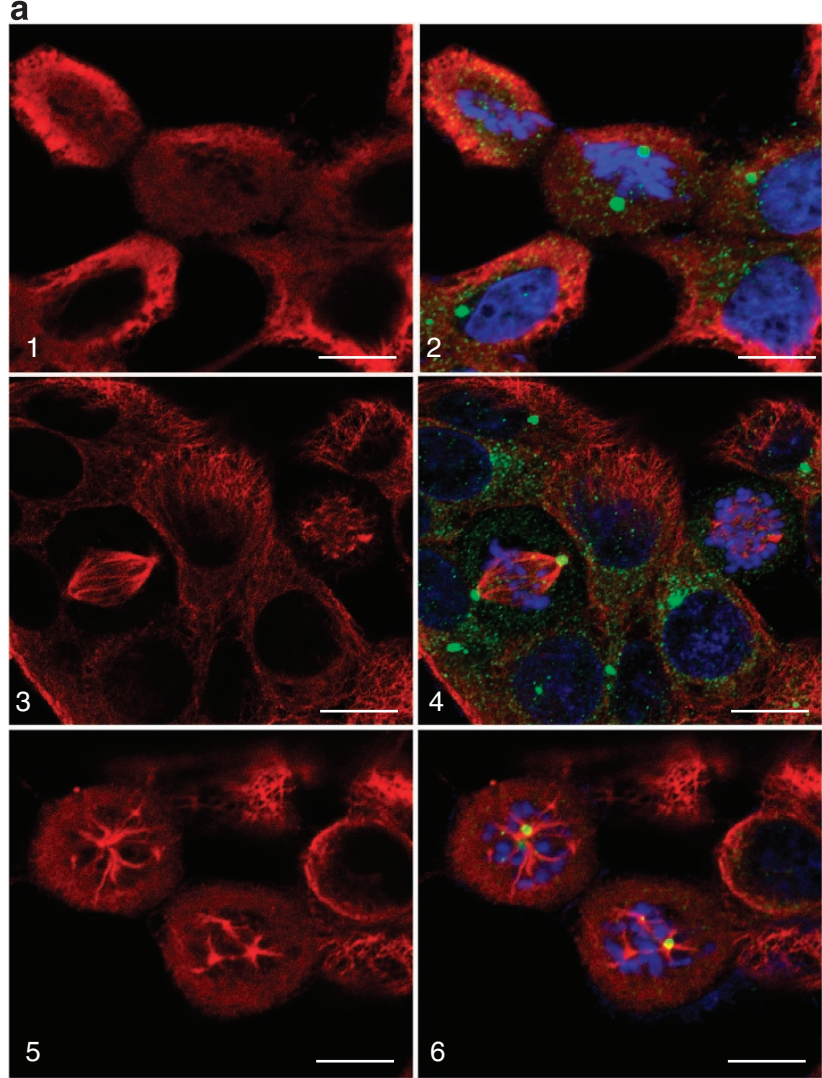

b

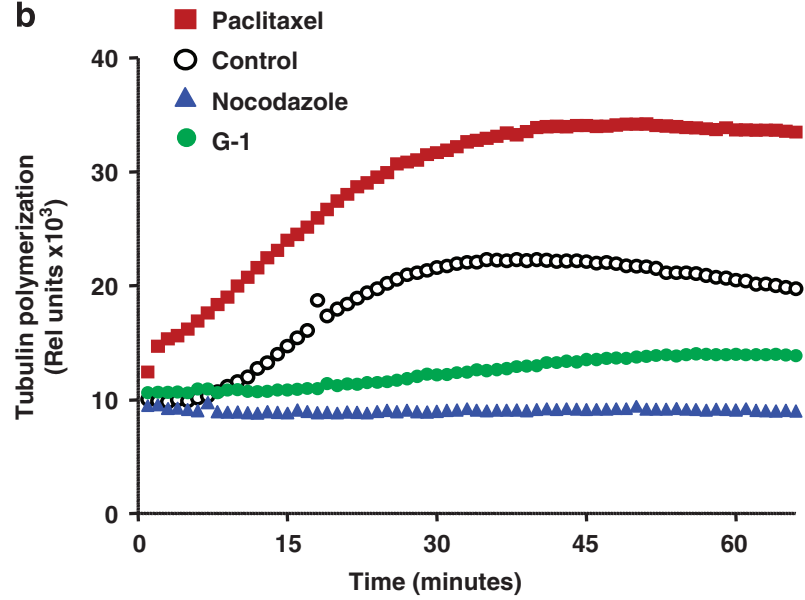

Figure 7 Effect of G-1 treatment on the tubulin polymerization and spindle formation. (a) The effect of G-1 on spindle formation in cultured IGROV-1 cells. a-1, $\mathrm{a}-3$, and $\mathrm{a}-5$ are IGROV- 1 cells stained with $\alpha$-tubulin; $\mathrm{a}-2$, $\mathrm{a}-4$, and $\mathrm{a}-6$ are IGROV- 1 cells stained with combination of $\alpha$-tubulin (red) and pericentrin-2 (green). The nucleus was stained with DAPI (blue). a-1 and a-2 show low-temperature-induced microtubule depolymerization in cultured IGROV-1 cells; a-3 and a-4 show that temperature recovery results in the polymerization of microtubule and formation of spindle in IGROV-1 cells. a-5 and a-6 show that addition of G-1 results in the disassembly of normal microtubules leading to the inhibition of spindle formation. Notice the formation of multiple spindle asters in the G-1-treated IGROV-1 cells. Scale bars, $10 \mu \mathrm{m}$. (b) In vitro microtubule assembly assay shows that G-1 (green graph) suppresses tubulin polymerization. Paclitaxel was used as a positive control (red graph). Nocodazole was used as a negative control (blue graph)

purchased from Abcam (Cambridge, MA, USA). The ECL (enhanced chemiluminescence) Advance Western Blotting Detection kit was purchased from GE Healthcare (Piscataway, NJ, USA). The Optitran Nitrocellulous Membrane was purchased from Schleicher \& Schuell Bioscience, Inc. (Dassel, Germany). The tubulin polymerization assay kit was purchased from Cytoskeleton, Inc. (Denver, CO, USA). The Vybrant MTT assay kit was purchased from Invitrogen. The Caspase-Glo $3 / 7$ assay kit was purchased from Promega (Madison, WI, USA). All other molecular-grade chemicals were purchased from Sigma-Aldrich, Fisher Scientific (Pittsburgh, PA, USA), or United States Biochemical Corp. (Cleveland, OH, USA).

Cell lines and culture. SKOV-3 and CAOV-3 cells were recently purchased from the American Type Culture Collection (Manassas, VA, USA). IGROV-1 cell line was kindly gifted by Dr. Reuda (Dr. Bo R Reuda, Vincent Center for Reproductive Biology, Massachusetts General Hospital, Boston, MA, USA). Cells were maintained in DMEM/F12 medium (Invitrogen) with $10 \% \mathrm{FBS}$ in a $37^{\circ} \mathrm{C}$ cell culture incubator. The medium was replaced with phenol red-free DMEM supplemented with $10 \%$ steroid-free FBS (Hyclone) $24 \mathrm{~h}$ before treatment. Cells were treated in fresh phenol red-free DMEM supplemented with steroid-free FBS $(5 \%)$ for indicated time points as shown in figure legends.

Cell proliferation and viability assay. To detect the effect of G-1 on ovarian cancer cell proliferation, $70 \%$ confluent cells were incubated in phenol redfree DMEM (5\% FBS, steroid-free) with or without G-1 for $60 \mathrm{~h}$ in concentrations indicated in figure legends. Cell morphology was recorded using an Olympus IX71 inverted microscope equipped with a DP73 digital camera (Olympus America Inc., Center Valley, PA, USA). The cell number was counted using a Countess Automated Cell Counter (Carlsbad, CA, USA).

An MTT assay was used to detect the effect of the GPER agonist G-1 on ovarian cancer cell viability. Cells were plated in 24-well plates and incubated to $\sim 60 \%$ confluence. Cells were then treated with or without G-1 for 24 or $48 \mathrm{~h}$. The MTT assay was performed using a Vybrant MTT Assay Kit according to the manufacturer's instructions.

Flow cytometry was used to detect the effect of G-1 treatment on the cell-cycle progression of ovarian cancer cells. Seventy percent confluent cells were incubated in phenol red-free DMEM (5\% FBS, steroid-free) with or without G-1 $(0-2 \mu \mathrm{M})$ for $24 \mathrm{~h}$. Cells were then trypsinized, fixed, and permeabilized with $70 \%$ ethanol overnight at $-20^{\circ} \mathrm{C}$. Cells were then labeled with propidium iodide at $37^{\circ} \mathrm{C}$ for $30 \mathrm{~min}$, and cell apoptosis and cell-cycle distribution were analyzed using flow cytometry.

Cell apoptosis was also monitored by detecting caspase 3/7 activity using a Caspase-Glo 3/7 assay kit. Ovarian cancer cells in 24-well culture plates were treated with or without G-1 at the indicated concentrations for designated time points as noted in the figure legends. Medium was removed and $75 \mu \mathrm{l}$ of serum-free medium with an equal volume of caspase $3 / 7$ assay reagent were directly added to the wells. After $30 \mathrm{~min}$ of agitation, luminescence was measured using a FLUOstar OPTIMA microplate reader.

Fluorescent immunocytochemistry to detect cellular localization of proteins related to cell mitosis and apoptosis. Cells were cultured on coverslips in six-well plates and treated with or without G-1 for the indicated time points as described in the figure legends. Cells were fixed with $4 \%$ paraformaldehyde at room temperature for $10 \mathrm{~min}$ and then blocked for $1 \mathrm{~h}$ with $10 \%$ normal donkey serum. Cells were then incubated overnight with a primary antibody at $4{ }^{\circ} \mathrm{C}$ in a humidified chamber. The next day, the non-binding primary antibodies were washed away. Cells were then incubated with the appropriate fluorescein-labeled secondary antibody at room temperature for $30 \mathrm{~min}$ in a humidified chamber. Nuclei were stained with DAPI. Cells on the coverslips were then mounted with Fluoromount-G (Southern Biotech, Birmingham, AL, USA). Images were captured with a Zeiss 710 Meta Confocal Laser Scanning microscope and were analyzed using the Zeiss Zen 2010 software (Carl Zeiss Microscope, LLC, NY, USA).

Western blot analysis to detect the expression and activation of mitosis entry and cell apoptosis-related proteins in ovarian cancer cell lines. To determine the expression and activation of apoptosis and/or the proteins related to the G2/M checkpoint in ovarian cancer cell lines, cultured cell lines were directly lysed in the culture dishes and homogenized by sonication in $100 \mu$ l of lysis buffer (10 mM Tris (pH 7.4), $100 \mathrm{mM} \mathrm{NaCl}, 1 \mathrm{mM}$ ethylenediaminetetraacetic acid, $1 \mathrm{mM}$ ethylene glycol tetraacetic acid, $1 \mathrm{mM} \mathrm{NaF}$, $20 \mathrm{mM} \mathrm{Na}_{4} \mathrm{P}_{2} \mathrm{O}_{7}, 1 \%$ Triton $\mathrm{X}-100,10 \%$ glycerol, $0.1 \%$ sodium dodecyl sulfate, and $0.5 \%$ deoxycholate) with protease inhibitor cocktails and phenylmethanesulfonyl fluoride. The homogenates were kept on ice for $20 \mathrm{~min}$ and then centrifuged at 12000 r.p.m. at $4^{\circ} \mathrm{C}$ for $15 \mathrm{~min}$. The supernatant was collected and 
the protein concentration was measured using a Micro BCA Protein Assay Kit (Pierce, Rockford, IL, USA) according to the manufacturer's instructions. Protein (20 or $40 \mu \mathrm{g}$ ) was fractioned using $10 \%$ polyacrylamide gels, electrotransferred to an Optitran nitrocellulous membrane, and probed overnight with primary antibodies at $4^{\circ} \mathrm{C}$. Peroxidase-conjugated donkey-anti-rabbit or peroxidaseconjugated donkey-anti-mouse secondary antibodies (Jackson ImmunoResearch Laboratories, Inc., West Grove, PA, USA) were applied to the membrane, and the bound secondary antibody was detected using the enhanced chemiluminescence advanced western blot detection kit. The signal was recorded and quantified using a UVP gel documentation system (UVP, Upland, CA, USA). The $\beta$-tubulin was used as protein loading controls. Each group had at least three sample replicates collected from three different experiments.

Microtubule reassembly assay. IGROV-1 cells were seeded on coverslips in six-well culture plates and incubated at $37^{\circ} \mathrm{C}$. When cells reached $70 \%$ confluence, three groups of cells were incubated on ice for $1 \mathrm{~h}$ to depolymerize the microtubules. After cold treatment, one group of cells was immediately fixed with $4 \%$ paraformaldehyde as a control. The cold medium in the other two groups was immediately replaced with media containing G-1 $(2 \mu \mathrm{M})$ or DMSO $(0.1 \%)$ pre-warmed to $37^{\circ} \mathrm{C}$. Cells were incubated at $37^{\circ} \mathrm{C}$ for $1 \mathrm{~h}$ and then fixed with $4 \%$ paraformaldehyde for $10 \mathrm{~min}$. Fixed cells were stained with antibodies against $\alpha$-tubulin to visualize the spindle microtubules, or with antibodies against pericentrin-2 to visualize the centrosomes. Nuclei were stained with DAPI. Images were captured using a Zeiss 710 Meta Confocal Laser Scanning microscope and analyzed with the Zeiss ZEN 2010 software.

Tubulin polymerization assay. The effects of G-1 treatment on tubulin polymerization was analyzed using a purified porcine tubulin and fluorescencebased tubulin polymerization assay kit (Cytoskeleton Inc.) according to the protocol provided by the manufacturer. G-1 $(5 \mu \mathrm{M})$ was added to the system. An equal concentration of DMSO was used as a normal control. The negative control was $100 \mathrm{nM}$ of nocodazole, which inhibits tubulin polymerization. A group with $3 \mu \mathrm{M}$ of paclitaxel, which stabilizes microtubule to interrupt microtubule dynamics, was also included as a positive control. The fluorescence was recorded using a Synergy Mx Monochromator-Based Multi-Mode Microplate Reader (BioTek Instruments, Inc., Winooski, VT, USA). The basic parameters for the assay were as follows: integration $-20 \mu \mathrm{s}$, gain $-80 \%$, shaking $-5 \mathrm{~s}$, excitation wavelength $-350 \mathrm{nM}$; emission wavelength $-440 \mathrm{nM}$, kinetic force -61 cycles of 1 reading/min, and reads per well -3 .

Statistics. All immunofluorescence localization and western blot experiments were repeated at least three times using samples from different experiments, and representative images are presented. The data from the cell-cycle distribution study was analyzed using two-way analysis of variance, Prism's multiple comparison post tests, and Bonferroni post tests. All other assays were repeated at least three times and the quantitative data were analyzed using one-way analysis of variance with Tukey post hoc test. A $P$-value $<0.05$ was considered significant.

\section{Conflict of Interest}

The authors declare no conflict of interest.

Acknowledgements. This work was supported by a grant from NICHD/NIH (1K99 HD059985 and 4R00 HD059985 to CW), funds from the Olson Center for Women's Health (CW and JSD), The Fred \& Pamela Buffett Cancer Center (CW), and Department of Veterans Affairs Biomedical Laboratory Research and Development Merit Review Research Program (JSD), and by Agriculture and Food Research Initiative Competitive grant no. 2011-67015-20076 from the USDA National Institute of Food and Agriculture (JSD). We thank Melody A Montgomery for her assistance in the preparation and editing of this manuscript. The human ovarian cancer IGROV-1 cell line was a generous gift from Dr. Bo R Rueda in Vincent Department of Obstetrics and Gynecology, Massachusetts General Hospital, Boston, MA, USA.

1. Prossnitz ER, Barton M. The G-protein-coupled estrogen receptor GPER in health and disease. Nat Rev Endocrinol 2011; 7: 715-726.

2. Deroo BJ, Korach KS. Estrogen receptors and human disease. J Clin Invest 2006; 116: $561-570$.
3. Bologa CG, Revankar CM, Young SM, Edwards BS, Arterburn JB, Kiselyov AS et al. Virtual and biomolecular screening converge on a selective agonist for GPR30. Nat Chem Biol 2006; 2: 207-212.

4. Dennis MK, Burai R, Ramesh C, Petrie WK, Alcon SN, Nayak TK et al. In vivo effects of a GPR30 antagonist. Nat Chem Biol 2009; 5: 421-427.

5. Dennis MK, Field AS, Burai R, Ramesh C, Petrie WK, Bologa CG et al. Identification of a GPER/GPR30 antagonist with improved estrogen receptor counterselectivity. J Steroid Biochem Mol Biol 2011; 127: 358-366.

6. Blasko E, Haskell CA, Leung S, Gualtieri G, Halks-Miller M, Mahmoudi M et al. Beneficial role of the GPR30 agonist G-1 in an animal model of multiple sclerosis. J Neuroimmunol 2009; 214: 67-77.

7. Albanito L, Madeo A, Lappano R, Vivacqua A, Rago V, Carpino A et al. G protein coupled receptor 30 (GPR30) mediates gene expression changes and growth response to $17 \mathrm{beta-}$ estradiol and selective GPR30 ligand G-1 in ovarian cancer cells. Cancer Res 2007; 67: 1859-1866.

8. Madeo A, Maggiolini M. Nuclear alternate estrogen receptor GPR30 mediates 17beta-estradiol-induced gene expression and migration in breast cancer-associated fibroblasts. Cancer Res 2010; 70: 6036-6046.

9. Pandey DP, Lappano R, Albanito L, Madeo A, Maggiolini M, Picard D. Estrogenic GPR30 signaling induces proliferation and migration of breast cancer cells through CTGF. EMBO J 2009; 28: 523-532.

10. He YY, Cai B, Yang YX, Liu XL, Wan XP. Estrogenic G protein-coupled receptor 30 signaling is involved in regulation of endometrial carcinoma by promoting proliferation, invasion potential, and interleukin- 6 secretion via the MEK/ERK mitogen-activated protein kinase pathway. Cancer Sci 2009; 100: 1051-1061.

11. Chevalier N, Vega A, Bouskine A, Siddeek B, Michiels JF, Chevallier D et al. GPR30, the non-classical membrane $G$ protein related estrogen receptor, is overexpressed in human seminoma and promotes seminoma cell proliferation. PLOS One 2012; 7: e34672.

12. Du GQ, Zhou L, Chen XY, Wan XP, He YY. The G protein-coupled receptor GPR30 mediates the proliferative and invasive effects induced by hydroxytamoxifen in endometrial cancer cells. Biochem Biophys Res Commun 2012; 420: 343-349.

13. Chan QK, Lam HM, Ng CF, Lee AY, Chan ES, Ng HK et al. Activation of GPR30 inhibits the growth of prostate cancer cells through sustained activation of Erk1/2, c-jun/c-fosdependent upregulation of p21, and induction of G(2) cell-cycle arrest. Cell Death Differ 2010; 17: 1511-1523.

14. Ariazi EA, Brailoiu E, Yerrum S, Shupp HA, Slifker MJ, Cunliffe HE et al. The G proteincoupled receptor GPR30 inhibits proliferation of estrogen receptor-positive breast cancer cells. Cancer Res 2010; 70: 1184-1194.

15. Wang C, Prossnitz ER, Roy SK. GPR30 expression is required for estrogen stimulation of primordial follicle formation in the hamster ovary. Endocrinology 149: 4452-4461 2008.

16. Wang C, Prossnitz ER, Roy SK. Expression of GPR30 in hamster ovary: differential regulation by gonadotropins and steroids hormones. Endocrinology 2007; 148: 4853-4864.

17. Pang $Y$, Thomas $P$. Role of $G$ protein-coupled estrogen receptor $1, G P E R$, in inhibition of oocyte maturation by endogenous estrogens in zebrafish. Dev Biol 2010; 342: 194-206.

18. Heublein S, Lenhard M, Vrekoussis T, Schoepfer J, Kuhn C, Friese K et al. The G-protein coupled estrogen receptor (GPER) is expressed in normal human ovaries and is upregulated in ovarian endometriosis and pelvic inflammatory disease involving the ovary. Reprod Sci 2012; 19: 1197-1204.

19. Smith HO, Arias-Pulido H, Kuo DY, Howard T, Qualls CR, Lee SJ et al. GPR30 predicts poor survival for ovarian cancer. Gynecol Oncol 2009; 114: 465-471.

20. Hans F, Dimitrov S. Histone H3 phosphorylation and cell division. Oncogene 2001; 20: 3021-3027.

21. Kolkova Z, Casslén V, Henic E, Ahmadi S, Ehinger A, Jirström K et al. The G proteincoupled estrogen receptor 1 (GPER/GPR30) does not predict survival in patients with ovarian cancer. J Ova Res 2012; 5: 9.

22. Preuss $\mathrm{U}$, Landsberg G, Scheidtmann KH. Novel mitosis-specific phosphorylation of histone H3 at Thr11 mediated by DIk/ZIP kinase. Nucleic Acids Res 2003; 31: 878-885.

23. Fukasawa K. Oncogenes and tumor suppressors take on centrosomes. Nat Rev Cancer 2007; 7: 911-924.

24. Albanito L, Lappano R, Madeo A, Chimento A, Prossnitz ER, Cappello AR et al. G-protein-coupled receptor 30 and estrogen receptor $\alpha$ are involved in the proliferative effects induced by atrazine in ovarian cancer cells. Environ Health Perspect 2008; 116 : 1648-1655.

25. Vivacqua A, Bonofiglio D, Albanito L, Madeo A, Rago V, Carpino A et al. $17 \beta$-estradiol, genistein and 4-hydroxytamoxifen induce the proliferation of thyroid cancer cells through the G-protein-coupled receptor GPR30. Mol Pharmacol 2006; 70: 1414-1423.

26. Chevalier N, Bouskine A, Fenichel P. Bisphenol A promotes testicular seminoma cell proliferation through GPER, the G-protein-coupled estrogen receptor. Int J Cancer 2012; 130: $241-242$.

27. Dong S, Terasaka S, Kiyama R. Bisphenol A induces a rapid activation of Erk1/2 through GPR30 in human breast cancer cells. Environ Pollut 2011; 159: 212-218.

28. Wang C, Lv XM, Jiang C, Davis JS. The putative G-protein coupled estrogen receptor (GPER) agonist G-1 suppresses proliferation of ovarian and breast cancer cells in a GPERindependent manner. Am J Transl Res 2012; 4: 390-402. 
29. Holm A, Grände PO, Ludueña RF, Olde B, Prasad V, Leeb-Lundberg LM et al. The G protein-coupled oestrogen receptor 1 agonist G-1 disrupts endothelial cell microtubule structure in a receptor-independent manner. Mol Cell Biochem 2012; 366: 239-249.

30. Satoh MS, Lindahl T. Role of poly(ADP-ribose) formation in DNA repair. Nature 1992; 356 356-358.

31. Oliver FJ, de la Rubia G, Rolli V, Ruiz-Ruiz MC, de Murcia G, Murcia JM. Importance of poly(ADP-ribose) polymerase and its cleavage in apoptosis. Lesson from an uncleavable mutant. J Biol Chem 1998; 273: 33533-33539.

32. Bennett V, Gilligan DM. The spectrin-based membrane skeleton and micron-scale organization of the plasma membrane. Annu Rev Cell Biol 1993; 9: 27-66.

33. Kaufmann SH, Desnoyers S, Ottaviano Y, Davidson NE, Poirier GG. Specific proteolytic cleavage of poly(ADP-ribose) polymerase: an early marker of chemotherapy-induced apoptosis. Cancer Res 1993; 53: 3976-3985.

34. Nicholson DW. Caspase structure, proteolytic substrates, and function during apoptotic cell death. Cell Death Differ 1999; 6: 1028-1042.

35. Lazebnik YA, Kaufmann SH, Desnoyers S, Poirier GG, Earnshaw WC. Cleavage of poly(ADP. ribose) polymerase by a proteinase with properties like ICE. Nature 1994; 371: 346-347.
36. Nicholson DW, Ali A, Thornberry NA, Vaillancourt JP, Ding CK, Gallant M et al. Identification and inhibition of the ICE/CED-3 protease necessary for mammalian apoptosis. Nature 1995; 376: 37-43.

37. Cregan SP, Dawson VL, Slack RS. Role of AIF in caspase-dependent and caspaseindependent cell death. Oncogene 2004; 23: 2785-2796.

38. Boutros R, Lobjois V, Ducommun B. CDC25 phosphatases in cancer cells: key players? Good targets? Nat Rev Cancer 2007; 7: 495-507.

39. Musacchio A, Salmon ED. The spindle-assembly checkpoint in space and time. Nat Rev Mol Cell Biol 2007; 8: 379-393.

cc) $\odot$ Cell Death and Disease is an open-access journal BY NC ND published by Nature Publishing Group. This work is licensed under a Creative Commons Attribution-NonCommercialNoDerivs 3.0 Unported License. To view a copy of this license, visit http://creativecommons.org/licenses/by-nc-nd/3.0/

Supplementary Information accompanies this paper on Cell Death and Disease website (http://www.nature.com/cddis) 